\title{
Aydın Koşullarında Pamuk Çeşitlerinde Su Stresinin Verim ve Verim Bileşenleri ile Lif Kalite Özellikleri Üzerine Etkileri
}

\author{
Safiye Pınar Tunalı ${ }^{1}$ Talih Gürbüz ${ }^{2}$ Selin Akçay ${ }^{1}$ Necdet Dağdelen $^{1 *}$ \\ ${ }^{1}$ Aydın Adnan Menderes Üniversitesi Ziraat Fakültesi Biyosistem Mühendisliği Bölümü, Koçarlı Aydın \\ 2 Aydın Adnan Menderes Üniversitesi Koçarlı Meslek Yüksekokulu, Koçarlı Aydın \\ *Sorumlu yazar: ndagdelen@adu.edu.tr
}

Geliș Tarihi: 02.04.2019

Kabul Tarihi: 26.06.2019

\section{$\ddot{O} z$}

$\mathrm{Bu}$ çalışma, kısıtlı sulamanın Carisma, Candia ve Gloria pamuk çeşitlerinde verim ve verim kalite parametreleri üzerine etkilerini belirlemek amacıyla 2018 yılında yapılmıştır. Aydın Adnan Menderes Üniversitesi Ziraat Fakültesi Araştırma ve Uygulama Çiftliği arazisinde yürütülen çalışma, tesadüf blokları deneme desenine göre üç tekerrürlü ve iki faktörlü olarak kurulmuştur. Damla sulama sistemiyle sulanan arazide parseller, A sınıfı buharlaşma kabından oluşan birikimli buharlaşmanın \%100, \%67, \%33 ve \%0'ı şeklinde 8 gün aralığında uygulanmıştır. Uygulanan sulama düzeyleri kütlü verimini ile bazı agronomik özellikler (bitkide koza sayısı; tek bitki verimi; koza kütlü pamuk ağırlığı; çırçır randımanı ve 100 tohum ağırlığı) ve lif kalite parametrelerini (lif uzunluğu, lif inceliği, lif kopma dayanıklılığı, üniformite değeri ve uzama katsayısı) önemli düzeyde etkilemiştir. Kütlü verimi açısından Carisma çeşidi Candia ve Gloria çeşidinden daha yüksek verime sahip olmuştur. Çalışmada en yüksek kütlü verimi Carisma çeşidinde sulama suyunun tam uygulandığı (\%100) konudan sağlanmıştır. Su kaynaklarının yetersiz olduğu şartlarda ise yine Carisma çeşidi öne çıkmakta ve \%67 düzeyinde su uygulanan konudan yüksek verim elde edilmiştir.

Anahtar kelimeler: Pamuk çeşidi, Damla sulama, Lif kalitesi, Kısıtlı sulama

\section{The Effects of Water Stress on Yield, Yield Component and Quality Parameters of Cotton Cultivars in Aydın Province}

Abstract

In order to observe the effects of deficit irrigation on yield, some agronomic and fiber quality parameters of Carisma, Candia and Gloria cotton cultivars. A field trial was conducted in year of 2018 at the Research and Application Farm of the Agriculture Faculty of Aydın Adnan Menderes University. The trial was designated in randomized complete block design with two factors and three replications. In the trials, irrigation water was applied to cotton cultivars using drip irrigation method as $100 \%, 67 \%, 33 \%$ and $0 \%$ of evaporation from Class A Pan corresponding to 8-day irrigation frequencies. The applications of water significantly affected seed cotton yield, various agronomic (number of bolls per plant, boll weight, number of sympodia, single plant yield, 100-seed weight and lint percentage) and cotton fiber quality (fiber length, fiber fineness, fiber strength, uniformity percentage and fiber elongation. It was determined cv. Carisma performed higher yields than cvs. Candia and Gloria. The highest yield was obtained from Carisma under full-irrigation (100\%) treatment. In the case of water scarcity, second highest yield was obtained from Carisma under deficit irrigation treatment (67\%). Keywords: Cotton cultivars, Drip irrigation, Fiber quality, Deficit irrigation

\section{Giriş}

Kuraklık, tarımsal üretimi sınırlayan en önemli faktörlerden biridir. İklim değişikliğinin bir sonucu olan bu sorun, son yıllarda etkisini gittikçe artırmaktadır. Ülkemizin de dâhil olduğu kurak yarı kurak iklime sahip çoğu bölgede düzensiz ve yetersiz yağışlar, depolanabilir su hacminin önemli ölçüde azalmasına neden olmaktadır. Bununla birlikte ülke nüfusunda meydana gelen artış içme ve kullanma suyu talebinde bir artışa neden olmuş, aynı zamanda sanayileşmenin hızla artması da endüstriyel amaçlı su kullanımında oldukça önemli bir artış yaratmıştır. Bu durum tarımsal amaçlı kullanılan suyun payını önemli ölçüde etkilemiştir. Mevcut su kaynaklarının en etkin şekilde kullanılması su kısıntısı çeken ülkelerin uygulaması gereken en önemli çözümdür. Tarımda etkin su kullanımının sağlanması için ise öncelikli olarak alınması gereken önlem, sulamaların hem bilinçli hem de tekniğine uygun bir şekilde yapılması olmalıdır. Bilindiği gibi yüzey sulama ile karşılaştırıldığında, basınçlı sulama sistemleri hem su hem de enerji tasarrufu sağlamasının yanında, minimum düzeyde su kaybı meydana gelen, çevre kirliliği yaratmayan, bununla birlikte hem ürün 
miktarı ve hem de kalitesinde artış meydana getiren sistemlerdir. Özellikle damla sulama sistemlerinin kullanılması ve sulama zamanı planlamasının doğru yapılması sayesinde su kaynakları etkin bir şekilde kullanılabilmekte ve böylece önemli miktarda su tasarrufu yapılabilmektedir. Sürdürülebilir tarım için en temel koşullardan biri \%90-95'e varan su uygulama randımanına sahip ve bitkilerin su kullanım etkinliğini arttıran damla sulama sistemleridir. Genel olarak su kaynaklarının kıt olduğu koşullarda yetiştirilen pamuk çeşitleri için damla sulama yöntemi kullanılarak sulama suyunun etkin kullanıldığ1 uygun sulama programlarının yapılması zorunludur. Tüm Türkiye'de olduğu gibi, yarı kurak ve kurak iklim özelliklerine sahip olan Aydın ili ve çevresinde de pamuk yetiştiriciliğinde sulamalar yüzey sulama yöntemleri ile yapılmaktadır. Yazlık bitki sınıfına giren pamuk bitkisi için sulama, yarı kurak iklim kuşağından, kurak iklimlere dek hemen her yerde temel öğelerden biri olmaktadır. Yapılan araştırmalar göstermiştir ki, sulu koşullarda yetiştirilen pamukta susuz koşullarda yetiştirilmesine göre 3-4 kat daha fazla verim elde edilmektedir (Doorenbos ve Kassam, 1979; Tüzel ve Ul, 2003).

Su stresinin pamukta neden olduğu verim kaybı, kuraklı̆̆ın görüldüğü yetişme dönemine ve kuraklık şiddetine göre değişmektedir. Pamuk bitkisinin su stresine karşı en hassas olduğu yetişme periyodu taraklanma başlangıcı ile ilk beyaz çiçeklerin görüldüğü dönem olduğu ve özellikle çiçeklenmenin en yoğun olduğu dönemde ortaya çıkacak kuraklığın verimi en fazla etkileyeceği bildirilmiştir (Krieg, 1997). Kuraklığın ortaya çıkmasıyla birlikte birim alandaki koza sayısının azalması, pamukta verim kaybı oluşmasının en önemli etkenidir (Pettigrew, 2004). Su stresi aynı zamanda meyve dalları üzerindeki koza dağılımını da etkilemektedir. Pamuk kütlü verimine katkıda bulunan kozalar, normal sulama koşullarında 2. ve 3. pozisyonlar ile 10. ve en üstte bulunan meyve dallarında iken, kurak iklim koşullarında bu kozalar dökülmekte ve verim sadece 1. pozisyondaki kozalar tarafindan belirlenmektedir (Gerik ve ark., 1996; Pettigrew, 2004). Kuraklık, verim ile birlikte lif kalitesini de olumsuz etkilemektedir. Pamuk liflerinin uzamaya başladığı dönemde ortaya çıkan kuraklık lif uzunluğunu, lif dayanıklılığını ve lif olgunluğunu olumsuz etkilediği bildirilmektedir (Johnson ve ark., 2002; Mert, 2005). Pettigrew (2004), 1998-2011 yılları arasında sekiz farklı pamuk çeşidini sulanan ve kurak koşullarda yetiştirerek verim, verim komponentleri, lif kalite özelliklerini incelmiştir. Çalışma sonucunda su dozunun artışıyla beraber koza sayısının $\% 30$, lif veriminin \%35 oranında arttığını buna karşın koza kütlü pamuk ağırlığında herhangi bir farklılığın olmadığını saptamıştır. Çırçır randımanı bakımından çeşitlerin farklı tepkiler gösterdiğini, sulama koşullarında çırçır randıman değerlerinin bazı çeşitlerde arttığı, bazı çeşitlerde ise azaldığını bildirmiştir. Lif kalite özellikleri bakımından ise lif uzunluğunun su stresi altında azaldığını, sulama yapıldığında arttığını bildirmiştir. Lifleri ile tekstil sanayisinde, çekirdek yağı ile bitkisel yağ sanayisinde, kapçık ve küspesi ile yem sanayisinde hammadde özelliği bulunan pamuk bitkisi önemli bir endüstri bitkisidir. Uluslararası Pamuk İstişare Komitesi (ICAC)'nin verilerine göre; ortalama 24,4 milyon ton lif pamuk elde edildiği bilinen dünyada, ortalama 32.1 milyon hektar alanda ekim yapılmaktadır. Dünyada pamuk ekim alanları açısından 9. sırada yer alan Türkiye'nin yıllık ekim alanı ortalama 462 bin ha'dır. TÜİK tarafından 2017/18 sezonu için hazırlanan rapora göre 2.450 ton kütlü pamuk üretimi yapıldığı, lif miktarının ise 882 bin ton ile dünyada ikinci sırada yer aldığı bildirilmiştir. Yine TÜIKK tarafından 2017 verilerine göre ülkemizde üretilen pamuğun \%56 ile en önemli oranı Güneydoğu Anadolu bölgesinde olduğu, bunu sırasıyla \%22 ile Ege Bölgesinin, \%18 ile Çukurova yöresinin ve \%1 ile Antalya yöresinin izlediği bildirilmiştir (Anonim, 2018a).

$\mathrm{Bu}$ çalışmanın amacı bölgemizde en fazla ekim alanına sahip Carisma, Candia ve Gloria pamuk çeşitleri için oluşturulan damla sulama konularının verim, verim bileşenleri ve lif kalite özellikleri üzerine olan etkilerini araştırmaktır.

\section{Materyal ve Yöntem}

$\mathrm{Bu}$ araştırma, 2018 yılı üretim sezonunda Adnan Menderes Üniversitesi Araştırma ve Uygulama arazilerinde yapılmıştır. Denizden 56 m yüksekte olan arazi, konum itibariyle Aşağı Büyük Menderes Havzası'nda, $37^{\circ} 51^{\prime}$ kuzey enlemi ile $27^{\circ} 51^{\prime}$ doğu boylamı üzerinde yer almaktadır (Anonim, 1995). Deneme alanı Akdeniz iklim kuşağında bulunmakta olup, kışlar 1lık ve yağışlı, yazlar sıcak ve kurak geçmektedir. Uzun yıllar ortalama sıcaklığı en düşük Ocak ayında $8.2{ }^{\circ} \mathrm{C}$, en yüksek Temmuz ayında $28,4{ }^{\circ} \mathrm{C}$ olarak tespit edilmiştir. Uzun yıllar ortalama yağış miktarı $645.1 \mathrm{~mm}$ 'dir. Ortalama nispi nem \%61,2 civarındadır (Anonim, 2018b). 
Çizelge 1'de deneme alanı içerisinde belli noktalardan alınan bozulmuş ve bozulmamış toprak örneklerine ait sonuçlar verilmiştir. Elde edilen verilere göre $0-120 \mathrm{~cm}$ toprak derinliğinde ölçülen kullanılabilir nem miktarı $221 \mathrm{~mm}$ olmuştur. Ayrıca araştırma alanı topraklarının çoğunda orta bünyenin hakim olduğu belirlenmiştir (Aksoy ve ark., 1998).

Çizelge 1. Deneme alanı topraklarının bazı fiziksel özellikleri

\begin{tabular}{|c|c|c|c|c|c|c|c|c|c|c|c|}
\hline \multirow{2}{*}{$\begin{array}{l}\text { Profil derinliği } \\
\text { (cm) }\end{array}$} & \multicolumn{3}{|c|}{ Bünye dağılımı (\%) } & \multirow{2}{*}{ Bünye sınıfi } & \multirow{2}{*}{$\begin{array}{c}\text { Hacim } \\
\text { ağırlık } \\
\left(\mathrm{g} \mathrm{cm}^{-3}\right)\end{array}$} & \multicolumn{2}{|c|}{$\begin{array}{c}* \text { Tarla } \\
\text { kapasitesi }\end{array}$} & \multicolumn{2}{|c|}{$\begin{array}{c}* \text { Devamli } \\
\text { solma noktas } 1\end{array}$} & \multicolumn{2}{|c|}{$\begin{array}{l}\text { Kullanilabilir su } \\
\text { tutma kapasitesi }\end{array}$} \\
\hline & Kum & Kil & Silt & & & $(\%)$ & $(\mathrm{mm})$ & $(\%)$ & $(\mathrm{mm}$ & $(\%)$ & $(\mathrm{mm})$ \\
\hline $0-30$ & 58,4 & 13,6 & 28,0 & Kumlu-Tinlı & 1,35 & 23,1 & 111,5 & 10,1 & 40,9 & 13,0 & 52,6 \\
\hline $30-60$ & 56,4 & 13,6 & 30,0 & Kumlu-Tinlı & 1,45 & 22,9 & 99,6 & 9,4 & 40,8 & 13,5 & 58,8 \\
\hline $60-90$ & 68,2 & 13,6 & 19,2 & Kumlu-Tinlı & 1,52 & 18,4 & 83,9 & 7,3 & 33,2 & 11,1 & 50,6 \\
\hline $90-120$ & 49,7 & 17,5 & 32,0 & Kumlu-Tinlı & 1,50 & 20,3 & 91,3 & 7,2 & 32,3 & 13,1 & 59,0 \\
\hline
\end{tabular}

*: Kuru ağırlık yüzdesi

Araştırma alanı topraklarının yapılan verimlilik analizlerine göre toprakların toplam tuz içerikleri \%0,015 gibi oldukça düşük olarak belirlenmiştir. Ayrıca \%1,05'lik değer ile organik madde içeriği açısından da toprakların oldukça fakir olduğu ortaya çıkmıştır. Bu durum alüviyal ana materyale sahip topraklarda çok sık rastlanan bir özelliktir (Aksoy ve ark., 1998).

Tesadüf blokları deneme desenine göre kurulan deneme, 3 tekerrürlü ve faktöriyel düzende ve iki faktörlü olarak yürütülmüştür. Oluşturulan bir deneme parselleri 8,0 x 4,2 m (6 sıra) olmak üzere toplam 33,60 $\mathrm{m}^{2}$ 'lik bir alanı kaplamaktadır. Bir deneme parselindeki bitki sıra aralığ $10,70 \mathrm{~m}$, sıra üzeri ise 0,20 m'dir. Çalışmada, sızma geçişlerini önlemek amacıyla bırakılan boşluklar, blok aralarında $3 \mathrm{~m}$, parsel aralarında ise $2 \mathrm{~m}$ olarak belirlenmiştir. Deneme alanına pamuk tohumları mibzer ile sıra aras $70 \mathrm{~cm}$ olacak şekilde ekilmiştir. Deneme parsellerinde ilk gübreleme ekimle birlikte $40 \mathrm{~kg} \mathrm{da}^{-1}(15-15-15)$ NPK gübresi şeklinde uygulanmıştır. İkinci çapalama ile birlikte bitki sıra aralarına toprak altına \%33'lük amonyum nitrat gübresi $25 \mathrm{~kg} /$ da olacak şekilde atılmıştır. Çalışmada 3 farklı pamuk çeşidi ve 4 farklı sulama düzeyi ele alınmıştır. Araştırma materyali olarak yüksek verim potansiyeline sahip Carisma, Candia ve Gloria pamuk çeşitleri kullanılmıştır. Çalışmada sabit 8 gün sulama aralığında A sınıfı buharlaşma kabından oluşan değerler dikkate alınarak sulama düzeyleri oluşturulmuştur. Buna göre 4 farklı sulama düzeyi (kpc-1: 1.00; kpc-2: 0.67, kpc-3: 0.33; kpc-4: yağışa dayalı-susuz) konuları üç tekrarlamalı olarak yürütülmüş̧ür. Çalışmada yer alan kpc-1: $1.00(\% 100)$ sulama düzeyi konularına sulama suyu eksiksiz uygulanmış; diğer konulara ise \%67; $\% 33$ ve $\% 0$ oranında sulama suyu uygulanmıştır.

Sulama suyu hesabı, esasları Kanber (1984)'de verilen açık su yüzeyi buharlaşması yöntemi ile yapılmıştır. Araştırmada, ilk sulama, etkili bitki kök bölgesi derinliğinde, kullanılabilir su tutma kapasitesinin \%40’ı tüketildiğinde yapılmış ve parsellere nem açığını kapatacak düzeyde sulama suyu uygulanmıştır. Ardışık sulamalar ise 8 gün sulama aralığında oluşan toplam buharlaşma değerleri dikkate alınarak yapılmışıtır. Çalışmada mevsimlik bitki su tüketimi değeri, toprak su dengesi eşitliği yardımıyla hesaplanmışıtır (James, 1988).

Damla sulama sistemi kullanılarak sulanan deneme alanında her parsele $16 \mathrm{~mm}$ dış çaplı polietilen (PE) lateral boruları her sıraya tek olacak şekilde döşenmiştir. Kullanılan lateraller içerisinde $2 \mathrm{~L} / \mathrm{h}$ debili içten geçik damlatıcılar $20 \mathrm{~cm}$ aralıklarla yerleştirilmiştir. Yine sulamaların kontrollü bir şekilde yapılabilmesi amacıyla her bir lateral hattı başına $16 \mathrm{~mm}$ çaplı vanalar takılmıştır.

Orta iki sırada yer alan bitkiler elle hasat edilmiş ve parsel kütlü verimleri bu hasat edilen kısım tartılarak elde edilmiştir. Hasatta aşağıda verilen bazı agronomik parametreler ile ilk hasatta her parselden 500 gram kütlü örneği alınarak bunlardan da yine aşağıda belirtilen lif kalite parametreleri belirlenmiştir. Buna göre verim ve verim parametrelerinden; kütlü pamuk verimi; bitkide koza sayısı; tek bitki verimi; koza kütlü pamuk ağırlığı; çırçır randımanı ve 100 tohum ağırlı̆̆ değerleri belirlenmiştir. Ayrıca her parselden alınan lif örneklerinin HVI (High Volume Instrument) aleti ile lif uzunluğu, lif inceliği, lif kopma dayanıklılı̆̆ı, üniformite değeri ve uzama katsayısı değerleri belirlenmiştir. TARIST bilgisayar paket programı kullanılarak, sulama konuları arasındaki farkları belirlemek amacıyla, yukarıda belirtilen tüm parametrelerden elde edilen veriler varyans analizine tabi tutulmuşlardır. Aynı program kullanılarak, farklı grupların belirlenmesinde ise \%5 önemlilik düzeyinde LSD testi uygulanmıştır (Açıkgöz ve ark., 1994). 


\section{Bulgular ve Tartışma}

Çalışmada ele alınan faktörlere göre pamuk kütlü verimleri arasındaki farklılıkları tespit etmek için varyans analizi yapılmıştır (Çizelge 2). Varyans analiz sonuçlarına göre, çeşitler ve sulama düzeyleri arasındaki farklılıklar $\mathrm{p}<0.01$ seviyesinde anlamlı bulunmuştur. Bununla birlikte deneme yılında Ç x SD interaksiyonu önemsiz çıkmıştır. Kütlü verimindeki farklılığın meydana geldiği çeşit ve sulama düzeylerini saptamak amacıyla LSD testi yapılmıştır. Buna göre sonuçlar çeşit açısından incelendiğinde birinci grubu Carisma oluştururken ikinci ve üçüncü grubu Candia ve Gloria çeşidi oluşturmuştur. Aynı çizelgede ortaya çıkan sonuçlar sulama düzeyleri bakımından incelendiğinde ise 4 farkl1 grup belirlenmiştir. Birinci grubu tüm gelişme dönemi boyunca tam sulama suyu uygulanan $\% 100$ konuları oluştururken; bunu $\% 67$ ve $\% 33$ düzeyinde sulama suyu uygulanan konular oluşturmuştur. Yağışa dayalı \%0 konusu ise son grubu oluşturmuştur. Araştırma sonuçları incelendiğinde, pamuk verim değerleri ile ilgili elde edilen sonuçların farklı sulama programları ile ilgili yapılan çalışmalardan elde edilen sonuçlarla benzerlik gösterdiği ortaya çıkmıştır (Yazar ve ark. 2002; Başal ve ark. 2009; Dağdelen ve ark. 2009a; Cave, 2013; Akçay ve Dağdelen 2017). Farklı çeşitlere göre sulanan konulara uygulanan sulama suyu miktarları 211-638 mm arasında değişmiştir. En yüksek sulama suyu, her üç çeşitte de \%100 konularına uygulanmıştır.

Çizelge 2. Araştırma konularına göre oluşan kütlü verim $(\mathrm{kg} / \mathrm{da})$ değerlerinin varyans analizi ve LSD testi sonuçları

$* \mathrm{P}<0.05 ; * * \mathrm{P}<0.01$; ns: önemsiz

\begin{tabular}{|c|c|c|}
\hline \multirow{3}{*}{ Çeşit } & Carisma & $470.4 a$ \\
\hline & Candia & $441.3 b$ \\
\hline & Gloria & $428.4 b$ \\
\hline F değeri (Ç) & & $* *$ \\
\hline LSD $\% 5$ & & 21.1 \\
\hline \multirow{4}{*}{ Su Düzeyi } & $\% 100$ & $605,4 a$ \\
\hline & $\% 67$ & $533,7 \mathrm{~b}$ \\
\hline & $\% 33$ & $451,8 \mathrm{c}$ \\
\hline & $\% 0$ & $196,0 \mathrm{~d}$ \\
\hline F değeri (SD) & & $* *$ \\
\hline LSD $\% 5$ & & 24,3 \\
\hline ÇxSD & & $\mathrm{ns}$ \\
\hline
\end{tabular}

LSD testine göre \% 5 düzeyinde oluşan gruplar farklı harfler ile verilmiştir.

Araştırmada dikkate alınan çeşit ve sulama düzeyleri faktörlerine göre elde edilen bazı agronomik özelliklere ilişkin varyans analizi ve bunların LSD testi sonuçları ise Çizelge 3'de verilmiştir. Çizelge 3'den izleneceği gibi, farklı çeşit ve sulama programlarına bağlı olarak koza sayısı 5-14 arasında değişmektedir. Koza sayısı dikkate alındığında; çeşitler arasındaki fark önemsiz bulunurken, sulama düzeyleri arasındaki fark $\mathrm{p}<0,01$ düzeyinde olmuştur. Uygulanan sulama suyu azalışına bağlı olarak koza sayısı azalmıştır. Genel olarak \%33 ve \%67 oranında sulama suyu uygulanan konulardan her üç çeşitte de daha az koza sayısı elde edilmiştir. Daha önce yapılan çalışmalarda da verimi etkileyen en önemli özelliğin koza sayısı olduğunu saptamıştır (Pettigrew, 2004). Bu konuda yapılan önceki çalışmalarda da su stresinin bitkide koza sayısını olumsuz yönde etkilediği bildirilmiştir (Hussein ve ark., 2011). Koza kütlü ağırlığı dikkate alındığında deneme yılı varyans analizi sonucuna göre gerek çeşitler gerekse de su düzeyleri arasındaki fark $\mathrm{p}<0.01$ düzeyinde anlamlı bulunmuştur. Elde edilen sonuçlar irdelendiğinde, Carisma çeşidi en yüksek koza kütlü ağırlığının elde edildiği çeşit olarak ortaya çıkmıştır. Bunun yanında sulama düzeyleri bakımından incelenen sonuçlara bakıldığında ise \%100 düzeyinde sulama suyu alan konular birinci grubu oluşturmuş̧ur. Genel olarak \%67 ve \%33 oranında sulama suyu uygulanan konulardan her üç çeşitte de daha düşük koza kütlü ağırlığı elde edilmiştir. En düşük koza kütlü ağırlığı ise susuz konudan elde edilmiştir. Aydın ovası koşullarında damla sulama yönteminin uygulandığı araştırmada farklı sulama uygulamalarına göre koza ağırlıkları ortalama olarak 3,51-6,18 gram arasında değişmiş̧tir (Başal ve ark., 2009). Önder ve ark. (2009)'in koza kütlü pamuk ağırlığının sulama miktarındaki artıştan olumlu yönde etkilediğini saptamıştır. 
Çizelge 3. Bazı agronomik özelliklerin varyans analizi ve LSD testi sonuçları

\begin{tabular}{|c|c|c|c|c|c|c|c|}
\hline & & $\begin{array}{l}\text { Koza sayis } 1 \\
\text { (adet) }\end{array}$ & $\begin{array}{l}\text { Koza kütlü } \\
\text { ağırlığ } \\
\text { (g) }\end{array}$ & $\begin{array}{c}\text { Meyve } \\
\text { dalı say1s1 } \\
\text { (adet) }\end{array}$ & $\begin{array}{c}\text { Tek bitki } \\
\text { verimi } \\
\text { (g/bitki) }\end{array}$ & $\begin{array}{l}\text { Yüz tohum } \\
\text { ağırlığ1 } \\
(\mathrm{g})\end{array}$ & $\begin{array}{c}\text { Çırçır } \\
\text { randımanı } \\
(\%)\end{array}$ \\
\hline \multirow{3}{*}{ Çeşit } & Carisma & 9,7 & $6,1 \mathrm{a}$ & $12,4 a$ & $68,0 \mathrm{a}$ & $9,60 \mathrm{a}$ & $41,90 \mathrm{~b}$ \\
\hline & Candia & 9,0 & $5,9 a$ & $10,6 b$ & $61,0 \mathrm{~b}$ & $9,58 \mathrm{a}$ & $42,51 \mathrm{a}$ \\
\hline & Gloria & 10,0 & $5,4 \mathrm{~b}$ & $11,1 b$ & $58,6 \mathrm{c}$ & $9,21 \mathrm{~b}$ & $42,06 \mathrm{ab}$ \\
\hline LSD \%5 & & 0,906 & 0,218 & 0,847 & 2,395 & 0,224 & 0,457 \\
\hline \multirow{4}{*}{$\begin{array}{l}\text { Sul. } \\
\text { Düz. } \\
\text { (SD) }\end{array}$} & $\% 100$ & $13,1 \mathrm{a}$ & $6,6 a$ & $15,4 \mathrm{a}$ & $82,3 \mathrm{a}$ & $10,16 a$ & $42,97 \mathrm{a}$ \\
\hline & $\% 67$ & $11,4 b$ & $5,9 b$ & $12,6 b$ & $75,8 b$ & $9,74 \mathrm{~b}$ & $42,44 b$ \\
\hline & $\% 33$ & $8,6 \mathrm{c}$ & $5,7 \mathrm{c}$ & $9,4 \mathrm{c}$ & $61,5 \mathrm{c}$ & $9,27 \mathrm{c}$ & $41,92 \mathrm{~b}$ \\
\hline & $\% 0$ & $5,1 d$ & $4,9 \mathrm{~d}$ & $8,1 \mathrm{~d}$ & $30,6 \mathrm{~d}$ & $8,68 \mathrm{~d}$ & $41,31 \mathrm{c}$ \\
\hline \multirow[t]{4}{*}{ LSD $\% 5$} & & 1,046 & 0,252 & 0,978 & 2,765 & 0,259 & 0,528 \\
\hline & Ç & ns & $* *$ & $* *$ & $* *$ & $* *$ & $*$ \\
\hline & SD & $* *$ & $* *$ & $* *$ & $* *$ & $* *$ & $* *$ \\
\hline & Ç x SD & ns & ns & ns & ns & ns & ns \\
\hline
\end{tabular}

$* \mathrm{P}<0.05 ; * * \mathrm{P}<0.01 ;$ ns: önemsiz

LSD testine göre \% 5 düzeyinde oluşan gruplar farklı harfler ile verilmiştir.

Meyve dalı varyans analizi sonucuna göre, çeşit ve su düzeyleri arasındaki fark $p<0,01$ düzeyinde önemli bulunmuştur. Çalışma sonucunda en yüksek meyve dalı sayısı Carisma çeşidinden elde edilmiştir. Yine tam sulama suyu uygulanan konularda en yüksek meyve dalı miktarı oluşurken, en az sulama suyu uygulanan konularda ise en düşük meyve dalı sayısı ortaya çıkmıştır. Nazilli koşullarında ise Nazilli-84 çeşidinin kullanıldı ğı çalışmada ortalama bitki başına meyve dalı sayısı 15,1-15,7 arasında değişmiştir (Özbek, 2000).

Yine aynı çizelgeden tek bitki verim değerleri incelendiğinde, çeşit ve su düzeyleri arasındaki fark $\mathrm{p}<0,01$ düzeyinde önemli bulunmuştur. Çalışmada tek bitki verimleri 28,4-87,9 g/bitki olarak belirlenmiştir. Çeşitler açısından sonuçlar incelendiğinde en yüksek tek bitki verimi Carisma çeşitinden elde edilmiştir. Yine tam sulama suyu alan (\%100) konularında en yüksek tek bitki verimi elde edilirken, en düşük tek bitki verimi ise sulama suyu uygulanmayan (\%0) konularda ortaya çıkmıştır. Elde edilen tek bitki verimleri sonuçları, Akçay ve Dağdelen (2018)' de verilen sonuçlar ile uyumluluk içerisindedir. Yüz tohum ağırlığı incelendiğinde, gerek çeşitler gerekse de su düzeyleri arasındaki fark $\mathrm{p}<0,01$ düzeyinde anlamlı bulunmuştur. En yüksek değerler $\% 100$ düzeyinde su alan konulardan elde edilmiştir. Diğer kalite özelliklerine benzer olarak tüm sulama konularında yüz tohum ağırlığı değerleri sulama suyu kısıntısına bağlı olarak azalma göstermiştir. Aydın koşullarında farklı sulama yöntemi ve sulama programlarına bağlı olarak 100 tohum ağırlığı değerleri Dağdelen ve ark. (2005) tarafindan 9,31-11,20 g arasında bulunmuş; Dağdelen ve ark. (2009b)'de ise 9,91-13,13 g olarak tespit edilmiştir. Deneme yılında çırçır randımanı değerleri incelendiğinde çeşit açısından $\mathrm{p}<0,05$ düzeyinde önemli bir fark tespit edilirken, su düzeyleri açısından ise $\mathrm{p}<0,01$ düzeyinde önemli bir fark tespit edilmiştir. Çeşitler açısından en yüksek değer Carisma çeşidinden elde edilirken, su düzeyleri açısından sonuçlar irdelendiğinde en yüksek değerler diğer verilerde olduğu gibi su kısıntısı yapılmayan tam sulama konularından elde edilmiştir. Yapılan çalışmalarda, tam sulama uygulamalarının olgunluk süresini etkilediğinden dolayı tohum ağırlığında ki artıştan dolayı çırçır randımanın artabileceği bildirilmiştir (Ertek ve Kanber, 2003; Başal ve ark., 2009).

Diğer taraftan araştırmadan elde edilen lif kalitesine ait varyans analiz sonuçları ile bunların LSD testine göre oluşan ortalamalar ve gruplar Çizelge 4'de verilmiştir.

Araştırmadan elde edilen lif inceliği değerlerine göre varyans analiz tablosu incelendiğinde, gerek çeşitler gerekse de su düzeyleri arasındaki fark $\mathrm{p}<0.01$ düzeyinde anlamlı bulunmuştur. Benzer şekilde bazı araştırıcılar farklı sulama uygulamalarının lif inceliği üzerine etkili olduğunu saptamışlardır (Hussein ve ark., 2011; Sobrinho ve ark., 2015; Akçay ve Dağdelen, 2018).

Lif uzunluğu değerleri açısından çeşitler arasındaki fark önemsizken, su düzeyleri arasındaki fark $\mathrm{p}<0.01$ düzeyinde bulunmuştur. Araştırmada su düzeylerindeki artışa bağlı olarak lif uzunluğu değerler artış göstermiştir. Daha önce yapılan çalışmalarda su stresinin lif uzunluğunu olumsuz yönde etkilediği bildirilmiştir (Pettigrew 2004; Hussein ve ark., 2011). Farklı bir çalışmada Dağdelen ve ark. (2005) ve Dağdelen ve ark. (2009b), Aydın koşullarında farklı sulama yöntemi ve sulama programlarının uygulandığı çalışmalarda lif uzunluğu değerlerini sırasıyla $26,4-30,0 \mathrm{~mm}$ ve $27,0-29,0$ 
mm olarak belirlemişlerdir. Çizelge 6'dan izleneceği gibi lif mukavemeti varyans analizi sonucuna göre, çeşitler arasındaki fark $\mathrm{p}<0,05$ düzeyinde önemli bulunurken su düzeyleri arasındaki fark ise önemsiz bulunmuştur. Sonuçlar çeşit açısından incelendiğinde birinci grubu Carisma oluştururken ikinci grubu Candia ve son grubu ise Gloria çeşidi oluşturmuştur. Daha önce yapılan çalışmalarda da sulama düzeyi ile lif mukavemeti arasında farklı sonuçlar bulunmuştur. Stiller ve ark. (2005) ve Pettigrew (2004)' de lif dayanıklılığının farklı su düzeylerinden etkilenmediği; Booker ve ark. (2006)'da ise su düzeyindeki azalmaya karşı lif dayanıklıllğının denemenin yürütüldüğü iki yıldan birinde arttığ üniformite değeri üzerine etkileri ise gerek çeşit gerekse de su düzeyleri açısından $p<0.01$ düzeyinde önemli bulunmuştur. Araştırma yılında bu değerler \%82,33-83,86 arasında değişmiştir. Daha önce bu konuda yapılan çalışmalarda farklı sonuçlar ortaya çıkmıştır. Su stresinin üniformite değerini azalttığını (Basal ve ark., 2009), bunun yanı sıra su stresinin üniformite değerine herhangi bir etki yapmadığını bildirmiş̧lerdir (Hussein ve ark., 2011).

Çizelge 4. Lif kalite özelliklerine ilişkin varyans analizi ve LSD testi sonuçları

\begin{tabular}{|c|c|c|c|c|c|c|}
\hline & & $\begin{array}{l}\text { Lif inceliği } \\
\text { (mic) }\end{array}$ & $\begin{array}{l}\text { Lif uzunluğu } \\
(\mathrm{mm})\end{array}$ & $\begin{array}{c}\text { Lif mukavemeti } \\
(\mathrm{g} / \mathrm{tex})\end{array}$ & $\begin{array}{c}\text { Üniformite } \\
(\%)\end{array}$ & $\begin{array}{c}\text { Uzama } \\
\text { katsayıs1 (elg) }\end{array}$ \\
\hline \multirow{3}{*}{ Çeşit } & Carisma & $4,69 \mathrm{a}$ & 28,53 & $32,10 \mathrm{a}$ & $83,12 \mathrm{c}$ & $7,17 \mathrm{a}$ \\
\hline & Candia & $4,53 b$ & 28,56 & $31,26 \mathrm{ab}$ & $83,61 b$ & $5,60 \mathrm{c}$ \\
\hline & Gloria & $4,52 \mathrm{~b}$ & 28,13 & $30,39 b$ & $84,10 \mathrm{a}$ & $6,30 b$ \\
\hline \multirow[t]{2}{*}{ LSD $\% 5$} & & 0,088 & 0,505 & 1,055 & 0,462 & 0,264 \\
\hline & $\% 100$ & $4,79 a$ & $30,31 \mathrm{a}$ & 31,66 & $84,82 \mathrm{a}$ & $6,65 \mathrm{a}$ \\
\hline \multirow{3}{*}{$\begin{array}{l}\text { Sul. Düz. } \\
\text { (SD) }\end{array}$} & $\% 67$ & $4,69 a$ & $28,82 b$ & 31,88 & $83,92 b$ & $6,45 \mathrm{ab}$ \\
\hline & $\% 33$ & $4,52 b$ & $27,83 \mathrm{c}$ & 31,20 & $83,19 \mathrm{c}$ & $6,28 b c$ \\
\hline & $\% 0$ & $4,31 \mathrm{c}$ & $26,66 \mathrm{~d}$ & 30,25 & $82,53 \mathrm{~d}$ & $6,04 c$ \\
\hline \multirow{4}{*}{ LSD $\% 5$} & & 0,101 & 0,584 & 1,218 & 0,533 & 0,304 \\
\hline & $\mathrm{C}$ & $* *$ & ns & $*$ & $* *$ & $* *$ \\
\hline & SD & $* *$ & $* *$ & ns & $* *$ & $* *$ \\
\hline & Ç x SD & ns & ns & ns & ns & ns \\
\hline
\end{tabular}

$* \mathrm{P}<0.05 ; * * \mathrm{P}<0.01 ;$ ns: önemsiz

LSD testine göre $\% 5$ düzeyinde oluşan gruplar farklı harfler ile verilmiştir.

\section{Sonuç ve Öneriler}

$\mathrm{Bu}$ çalışma; Aydın ovası koşullarında yaygın olarak tarımı yapılan Carisma, Candia ve Gloria pamuk çeşitlerinde damla sulama sistemlerinde farklı su düzeylerinin kütlü verimi ile verim bileşenleri ve lif kalite özellikleri üzerine etkilerini saptamak amacıyla yürütülmüştür. Pamuk çeşitleri ve sulama düzeyleri arasındaki fark $\mathrm{p}<0.01$ seviyesinde anlamlı bulunmuştur. Bununla birlikte deneme yılında Ç x SD interaksiyonu da önemsiz çıkmıştır. Buna göre sonuçlar çeşit açısından incelendiğinde birinci grubu Carisma oluştururken ikinci ve üçüncü grubu Candia ve Gloria çeşidi oluşturmuştur. Aynı çizelgeden, sonuçlar su düzeyleri bakımından irdelendiğinde ise 4 farklı grup belirlenmiştir. Tüm gelişme dönemi boyunca tam sulama suyu uygulanan \%100 konuları birinci grubu oluştururken; bunu $\% 67$ ve \%33 düzeyinde sulama suyu uygulanan konular oluşturmuştur. Yağış̧a dayalı \%0 konusu ise son grubu oluşturmuştur. Koza sayısı dikkate alındığında; çeşitler arasındaki farklılık önemsiz bulunurken, su düzeyleri arasındaki fark $\mathrm{p}<0,01$ düzeyinde olmuştur. Koza kütlü ağırlığ 1 dikkate alındığında deneme yılı varyans analizi sonucuna göre gerek çeşitler gerekse de su düzeyleri arasındaki fark $\mathrm{p}<0.01$ düzeyinde anlamlı bulunmuştur. Farklı çeşitler değerlendirildiğinde, en yüksek koza kütlü ağırlığı Carisma çeşidinden elde edilmiştir. Tek bitki verim değerleri incelendiğinde, her iki yılda da çeşit ve su düzeyleri arasındaki fark $\mathrm{p}<0,01$ düzeyinde önemli bulunmuştur. Çalışmada tek bitki verimleri 28,4-87,9 g/bitki olarak belirlenmiştir. Çırçır randımanı değerleri incelendiğinde çeşit açısından $\mathrm{p}<0.05$ düzeyinde önemli bir fark tespit edilirken, su düzeyleri açısından ise $\mathrm{p}<0,01$ düzeyinde önemli bir fark tespit edilmiştir. En yüksek verim değeri Carisma çeşidinden elde edilirken, en yüksek verim değeri su düzeyi açısından su kısıntısı yapılmayan, tam sulama konularından elde edilmiştir. Araştırmadan elde edilen lif inceliği değerlerine göre varyans analiz tablosu incelendiğinde, gerek çeşitler gerekse de su düzeyleri arasındaki fark $\mathrm{p}<0,01$ düzeyinde anlamlı bulunmuştur. Lif uzunluğu değerleri sulama konularına göre 26,31-30,51 mm arasında değişmiştir. Deneme yılında çeşitler arasındaki fark önemsizken, su düzeyleri arasındaki fark $\mathrm{p}<0,01$ düzeyinde bulunmuştur. Lif mukavemeti değerleri 29,9-33,3 gtex $^{-1}$ arasında değişmiştir. Lif mukavemeti varyans analizi sonucuna 
göre, çeşitler arasındaki fark $\mathrm{p}<0,05$ düzeyinde önemli bulunurken su düzeyleri arasındaki fark ise önemsiz bulunmuştur. Araştırma konularının üniformite değeri üzerine etkileri ise gerek çeşit gerekse de su düzeyleri açısından $\mathrm{p}<0,01$ düzeyinde önemli bulunmuştur. Araştırma yılında bu değerler \%82,33-83,86 arasında değişmiştir. Çalışmada, kopma anındaki lif uzama oranı \%5,2-7,3 arasında değişmiştir. Araştırma konularının kopma anındaki lif uzama oranı üzerine etkileri gerek çeşit gerekse de su düzeyleri açısından $\mathrm{p}<0,01$ düzeyinde önemli bulunmuştur.

Genel olarak değerlendirildiğinde; sulama düzeylerinin kütlü verimi ile verim bileşenleri ve lif kalitesi üzerine olumlu etkide bulunduğu açık bir biçimde ortaya konulmuştur. Bu nedenle Aydın Ovası koşullarında pamuk yetiştiriciliğinde verim potansiyeli yüksek pamuk çeşitlerinde damla sulama uygulamaları sürdürebilir tarım açısından son derece önemlidir.

\section{Teşekkür:}

Bu çalışmanın yürütülmesinde, Aydın Adnan Menderes Üniversitesi Bilimsel Araştırma Projeleri (BAP) birimi (ZRF-17059) tarafından verilen destek için teşekkür ederiz.

\section{Kaynaklar}

Açıkgöz, N., Aktaş, M.E., Mokhaddam, A.F., Özcan, K., 1994. Tarist an agrostatistical package programme for personel computer. E.Ü.Z.F. Tarla Bitkileri Kongresi. İzmir, Turkey.

Akçay, S., Dağdelen, N., 2017. Water productivity and fiber quality parameters of deficit irrigated cotton in a semi-arid environment. Fresenius Environmental Bulletin. 26 (11): 6500-6507.

Akçay, S., Dağdelen, N., 2018. Effect of deficit urrigation on some agronomic traits of cotton (Gossypium hirsutum L.) cultivars differing in maturity. International Journal of Engineering Science Invention. 7 (6: IV): 54-59.

Aksoy, E., Aydın, G., Seferoğlu, S., 1998. Adnan Menderes Üniversitesi Ziraat Fakültesi Arazi Topraklarının Önemli Karakteristikleri ve Sınıflandırılması. Ege Bölgesi 1. Tarım Kongresi. Cilt: 2. 469-477. Aydın.

Anonim, 1995. Tarım ve Köyişleri Bakanlığı Aydın İl Müdürlüğü Çalışma Raporu. S. 1-2. Aydın.

Anonim, 2018a. T.C. Gümrük ve Ticaret Bakanlığı Kooperatifçilik Genel Müdürlüğü 2017 Yılı Pamuk Raporu.

Anonim, 2018b. Aydın İli Tarım Master Planı. Aydın Tarım İl Müdürlügü̈, Aydın.

Başal, H., Dağdelen, N., Ünay, A., Yılmaz, E., 2009. Effects of deficit drip irrigation ratios on cotton (Gossypium hirsutum L.) yield and fiber quality. J. Agron. Crop Sci. 195 (1): 19-29.

Booker, J.O., Bordovsky, J., Lascano, R.J., Segarra, E., 2006. Variable rate irrigation on cotton lint yield and fiber quality. Beltwide cotton conferences. January 3-6, San Antonio, Texas.

Cave, J., 2013. Cotton lint yield, fiber quality, and water-use efficiency as influenced by cultivar and irrigation level. Texas Tech University, USA, Master of Sciences. P 192.

Dağdelen, N., Yılmaz, E., Sezgin, F., Gürbüz, T., 2005. Karık yöntemiyle sulanan pamukta farklı sulama düzeylerinin kütlü kalitesi ve bazı agronomik özellikler üzerine etkisi. IV.GAP Tarım Kongresi. 16511658. 21-23 Eylül 2005, Şanliurfa.

Dağdelen, N., Başal, H., Yılmaz, E., Gürbüz, T., Akçay, S., 2009a. Different drip irrigation regimes affect cotton yield, water use efficiency and fiber quality in western Turkey. Agric. Water Manag. 96: 111-120.

Dağdelen, N., Sezgin, F., Gürbüz, T., Yılmaz, E., Akçay, S., 2009b. Farklı sulama aralığı ve sulama düzeylerinin pamukta bazı verim özellikleri ve lif kalitesi üzerine etkisi. ADÜ Ziraat Fakültesi Dergisi. 6 (1): 53-61.

Doorenbos, J., Kassam, A.H., 1979. Yield Response to Water. FAO Irr. and Drain. Paper, No: 33. p.193. Rome.

Ertek, A., Kanber, R., 2003. Effects of different irrigation programs on the lint out-turn of cotton under drip irrigation. KSU J. Science and Engineering. 6: 106-116.

Gerik, T. J., Faver, K. L., Thaxton, P. M., El-Zik, K. M., 1996. Late season water stress in cotton: I. plant growth, water use, and yield. Crop Sci. 36: 914-921.

Hussein, F., Janat, M., Yakoub, A., 2011. Assessment of yield and water use efficiency of drip- irrigated cotton (Gossypium hirsutum L.) as affected by deficitirrigation. Exp. Agri. Israel. 9 (1): 121-128.

Johnson, R. M., Downer, R. G., Bradow, J. M., Bauer, P. J., Sadler, E. J., 2002. Variability in cotton fiber yield, fiber quality, and soil properties in a southeastern coastal plain. Agron. J. 94: 1305-1316.

James, L.G., 1988. Principles of Farm Irrigation System Design. John Wiley and Sons. Inc, Newyork.

Kanber, R., 1984. Çukurova koşullarında açık su yüzeyi buharlaşmasından (class a pan) yararlanarak birinci ve ikinci ürün yerfıstığının sulanması. Bölge Toprak Su Araşt. Enst. Müd. Yayınları. Tarsus. 78 (33): 1151.

Krieg, D.R., 1997. Genetic and environmental factors affecting productivity of cotton. Proc. Beltwide Cotton Prod. Res. Conf. p: 1347.

Mert, M., 2005. Irrigation of cotton cultivars improves seed cotton yield, yield components and fibre properties in the Hatay region, Turkey. Acta Agriculturae Scandinavica. B. 55: 44-50. 
ÇOMÜ Zir. Fak. Derg. (COMU J. Agric. Fac.)

2019: 7 (1): 161-168

ISSN: 2147-8384 / e-ISSN: 2564-6826

doi: 10.33202/comuagri.548023

Önder, D., Akiscan, Y., Önder, S., Mert, M., 2009. Effect of different irrigation water level on cotton yield and yield components. African Journal of Biotechnology. 8 (8): 1536-1544.

Özbek, N., 2000. Farklı pamuk çeşitlerinde ilk sulama zamanlarının bazı agronomik ve teknolojik özellikler ile koza tutumuna etkisi. Aydın Adnan Menderes Üniversitesi, Fen Bilimleri Enst. Yüksek Lisans Tezi.

Pettigrew, W.T., 2004. Moisture deficit effect on cotton lint yield, yield components, and boll distribution. Agron. J. 96: 377-383.

Sobrinho, F., Guerra, H., Araujo, W., Pereira, J., Zonta, J., Bezerra, J., 2015. Fiber quality of upland cotton under different irrigation depths. Revista Brasileira de Engenharia Agricola e Ambiental. 19 (11): 1057-1063.

Stiller, W.N., Read, J.J., Constable, G.A., Reid, P.E., 2005. Selection for water use efficiency traits in a cotton breeding program: cultivar differences. Crop Science. 45: 1107-1113.

Tüzel, İ.H., Ul, M.A., 2003. Pamuk sulaması. Pamukta Eğitim Semineri. 83-92.14-17 Ekim 2003, İzmir.

Yazar, A., Sezen, S.M., Sesveren, S., 2002. LEPA and trickle 1rrigation of cotton in the Southeast Anatolia Project (GAP) area in Turkey. Agricultural Water Management. 54 (3): 189-203. 